\title{
Biochemical response of three Vigna mungo varieties (T9, RBU38 and VM4) under drought stress
}

\author{
Sonali Pandey and Dipjyoti Chakraborty ${ }^{凶}$
}

\begin{abstract}
Plants apply several strategies that are developed during their evolution and artificial domestication to overcome biotic and abiotic stresses. Among eminent environmental threats drought stress is a major factor that affects plants at physiological, biochemical and molecular level. Blackgram (Vigna mungo) is an important pulse crop but its productivity is adversely affected by drought. In the present work, different cultivars of blackgram i.e. T9, RBU38 and VM4 are taken to find out the effects of drought stress by the estimation of different biochemical parameters to better understand biochemical pathway modulations under stress and its possible mitigation. Damage to photosynthetic machinery as evident by decrease in chlorophyll content and loss of membrane integrity in the plants under drought stress. The adverse effects of drought on the plants were averted to a certain extent in RBU38 by activation of defence signalling through $\mathrm{H}_{2} \mathrm{O}_{2}$ at lower concentration, which proved damaging at high concentration for T9 and VM4 and a concurrent increase in proline content which may provide protection against oxidative stress. This study suggests that drought modulated biochemical parameters can be used as reliable indices for selection of genotypes with a better stress tolerance.
\end{abstract}

Keywords: Vigna mungo; drought stress; ROS

Received: 15 November 2014

Accepted revised version: 02 January 2015

Published online: 04 April 2015

(C) Pandey and Chakraborty (2015)

Publisher: Horizon e-Publishing Group

\section{CITATION}

Pandey, S. and D. Chakraborty. 2015. Biochemical response of three Vigna mungo varieties (T9, RBU38 and VM4) under drought stress. Plant Science Today 2(2): 60-64. doi: 10.14719/pst.2015.2.2.99

AUTHOR'S AFFILIATION

Department of Bioscience and Biotechnology, Banasthali Vidyapith, Rajasthan 304022, India

CORRESPONDENCE

$\triangle$ Dipjyoti Chakraborty - Email: dciitkgp@gmail.com

\section{Introduction}

India is a developing country where a large population is vegetarian and food legumes, mainly the grains or pulses are an important constituent of the diet. Pulses are cheap and have a high nutrient content including starch, protein dietary fiber, oligosaccharides, phytochemicals and minerals (Borade et al., 1984). Vigna mungo (L.) Hepper, commonly known as blackgram, contributes $20 \%$ to overall world pulse production (Saravanakumar et al., 2007). In India it is the third important pulse crop (Arulbalachandran et al., 2010). However, production of blackgram is adversely affected by various environmental stress factors, especially drought that reduce yield (Souframanien and Gopalakrishna, 2006; Kundu et al., 2011; Pandey et al., 2014). Various strategies as drought escape, drought avoidance and drought tolerance are used by plants to complete their life cycle under stress. Plant responses are complex and diverse as they adapt to drought stress as evident in an immediate change in the phosphorylation status of a protein within minutes followed by modulation in gene expression. The response varies according to species and genotype of plants, length and severity of drought, age and stage of development of plants, organ and cell type (Bray, 1997; Alpert and Oliver, 2002; Walters et al., 2002). Plants try to restore the osmotic as well as ionic equilibrium of the cell (cellular homeostasis) and control the damages via decrease in the rate of ROS generation, accelerating ROS scavenging and increasing the recovery of damaged cellular components (Wang et al., 2002).

The aim of the present study is to screen different varieties of Vigna mungo viz., T9, RBU38 and VM4 at early growth stage for biochemical response to short-term drought condition. T9 is susceptible to MYMIV (Mungbean Yellow Mosaic India Virus) while VM4 is MYMIV-resistant; the characteristics of these varieties vis-à-vis water deficit are not known. RBU 38 is a widely cultivated variety in semi-arid regions of Rajasthan and is known for its drought tolerant quality. As VM4 is resistance to MYMIV, 
its response to drought would enable to know its adaptability to drought stress for possible introduction.

\section{Materials and Methods}

\section{Plant material and procedure}

Three varieties of blackgram (T9, RBU38 and VM4) were used for the present work. Seeds of RBU-38 variety were obtained from Krishi Vigyan Kendra (KVK), Banasthali, Rajasthan. Seeds of T9 and VM4 varieties were obtained from Division of Plant Biology, Bose Institute, Kolkata, India.

Mature seeds of each variety were surface sterilized with $0.1 \%$ mercuric chloride $(\mathrm{w} / \mathrm{v})$ for $5 \mathrm{~min}$, washed thoroughly with sterile distilled water and soaked in distilled water to germinate in plant growth chamber at 28 $\pm 2^{\circ} \mathrm{C}$ under a $16 \mathrm{~h}$ photoperiod. The germinated seedlings were planted in plastic pots containing soil bed moistened with distilled water. The soil was obtained from the experimental plot of KVK, Banasthali. The soil properties
Fresh leaves (0.1g) were freeze dried in liquid nitrogen and homogenized in $2 \mathrm{ml}$ of chilled $80 \%(\mathrm{v} / \mathrm{v}$ ) aqueous acetone and centrifuged at $10000 \mathrm{~g}$ for $10 \mathrm{~min}$ at $4^{\circ} \mathrm{C}$. The absorbance of the supernatant was measured at three wavelengths of 645,652 and $663 \mathrm{~nm}$ by using a spectrophotometer (Systronics - 2202).

\section{Hydrogen peroxide $\left(\mathrm{H}_{2} \mathrm{O}_{2}\right)$ content}

$\mathrm{H}_{2} \mathrm{O}_{2}$ content was determined following the method of Alexieva et al. (2001) and calculated using the extinction coefficient $\left(\mathrm{E}=0.28 \mu \mathrm{mol} \mathrm{cm}{ }^{-1}\right)$.

\section{Total phenolic content}

The method of Singleton et al. (1999) as modified by Chakraborty et al. (2008) was used to determine the total phenolic content and expressed as gallic acid equivalent (GAE).

\section{Proline content}

Proline content was determined by following the method of Bates et al. (1973).

Table 1: Effect of drought stress on chlorophyll contents ( $\mathrm{mg} \mathrm{g}^{-1} \mathrm{fw}$ ) of $V$. mungo leaves (cV. T9, RBU38 and VM4).

\begin{tabular}{llll}
\hline \multirow{2}{*}{ Treatments } & Chl a & Chl b & Total Chl \\
\cline { 2 - 4 } & $\mathbf{m g} / \mathbf{g ~ f w} \mathbf{~ w}^{*}$ & $\mathbf{~ g} / \mathbf{g ~ f w ^ { * }}$ & $\mathbf{m g} / \mathbf{g}$ fw* \\
\hline & & & \\
T9 & $0.96 \pm 0.018^{\mathrm{d}}$ & $0.34 \pm 0.006^{\mathrm{de}}$ & $1.29 \pm 0.023^{\mathrm{e}}$ \\
21DAS & $0.34 \pm 0.005^{\mathrm{de}}$ & $0.75 \pm 0.015^{\mathrm{a}}$ \\
27DAS (D) & $0.41 \pm 0.009^{\mathrm{a}}$ & $0.33 \pm 0.001^{\mathrm{d}}$ & $0.84 \pm 0.011^{\mathrm{b}}$ \\
\hline RBU38 & & & \\
21DAS & $1.43 \pm 0.128^{\mathrm{e}}$ & $0.42 \pm 0.032^{\mathrm{f}}$ & $1.85 \pm 0.099 \mathrm{~g}$ \\
27DAS (D) & $1.36 \pm 0.065^{\mathrm{e}}$ & $0.36 \pm 0.030^{\mathrm{e}}$ & $1.72 \pm 0.041^{\mathrm{f}}$ \\
28DAS (R) & $1.40 \pm 0.031^{\mathrm{e}}$ & $0.42 \pm 0.008^{\mathrm{f}}$ & $1.82 \pm 0.024 \mathrm{~g}$ \\
\hline VM4 & & & \\
21DAS & $1.03 \pm 0.003^{\mathrm{d}}$ & $0.26 \pm 0.006^{\mathrm{c}}$ & $1.29 \pm 0.008^{\mathrm{e}}$ \\
27DAS (D) & $0.77 \pm 0.022^{\mathrm{c}}$ & $0.14 \pm 0.014^{\mathrm{a}}$ & $0.92 \pm 0.035^{\mathrm{c}}$ \\
28DAS (R) & $0.82 \pm 0.007^{\mathrm{c}}$ & $0.20 \pm 0.016^{\mathrm{b}}$ & $1.02 \pm 0.022^{\mathrm{d}}$ \\
\hline
\end{tabular}

* Values are mean \pm standard deviation (SD); data followed by same alphabets are not significantly different at $\mathrm{p} \leq 0.05$ according to ANOVA and DMRT for each column. DAS: days after sowing, D: 3 days under drought stress, R, recovery.

are as follows: Soil contained nitrogen $220 \mathrm{Kgha}^{-1}$, phosphorus $14.50 \mathrm{Kgha}^{-1}$, potassium $240 \mathrm{Kgha}^{-1}$, sulphur 12.5 $\mathrm{Kgha}^{-1}$, iron $24.5 \mathrm{mgkg}^{-1}$, copper $4.60 \mathrm{mgkg}^{-1}$, manganese $12.20 \mathrm{mgkg}^{-1}$, zinc $4.00 \mathrm{mgkg}^{-1}$, electrical conductivity 1.40 , bulk density $1.68 \mathrm{mgm}^{-3}$, organic carbon $3.50 \mathrm{gkg}^{-1}$ and pH 7.90 (data obtained from KVK).

Three week old plants (21 DAS) were used for the experiments. Plants were divided into two sets each with 12-15 replicate plants: set 1 - healthy control plants which were waters regularly and set 2- water withhold from 24DAS to 27 DAS. All the biochemical parameters are studied after 3 days of short-term drought stress (27DAS) and $24 \mathrm{hr}$ after recovery (28DAS).

\section{Chlorophyll content}

Chlorophyll a, chlorophyll b and total chlorophyll content was determined using the method of Arnon et al., 1949.

\section{Lipid peroxidation}

Lipid peroxidation was determined following the method of De Vos et al. (1989) and calculated by using extinction coefficient (155 $\left.\mathrm{mM}^{-1} \mathrm{~cm}^{-1}\right)$.

\section{Statistical analyses}

Analysis of Variance (ANOVA) - Duncan multiple range test (DMRT) is used to find out the significant differences between means $(\mathrm{p}<0.05)$ using SPSS software (16.0 SPSS Inc.).

\section{Results and Discussion}

The cultivars of blackgram i.e. T9, RBU38 and VM4 that were subjected to short-term drought stress of three days showed a rapid loss in chlorophyll a and total chlorophyll content (Table 1). Chlorophyll content of RBU38 plants 
was least affected when compared to plants of T9 and VM4. Similar decrease in chlorophyll content also observed by Baisak et al. (1994), Alam et al. (2013) and Pandey et al. (2014) under drought stress. On recovery, chlorophyll content increased in all varieties of blackgram but was less than that of respective control plants. All photosynthetic components were damaged under stress conditions i.e. ETC of thylakoid, carbon reduction cycle and tissue (Apel and Heribert, 2004; Quan et al., 2008) it is harmful for plants and sometimes lead to cell death (Trippi et al., 1989; Smirnoff, 1993). At lower concentration it acts as signal molecule against stress conditions and work for plant defence mechanisms and at higher concentration or its long persistence can damage the plant cells. As RBU-38 plants are tolerant to drought as compared to T9 and VM4, lower $\mathrm{H}_{2} \mathrm{O}_{2}$ content was observed whereas, in T9 and VM-4
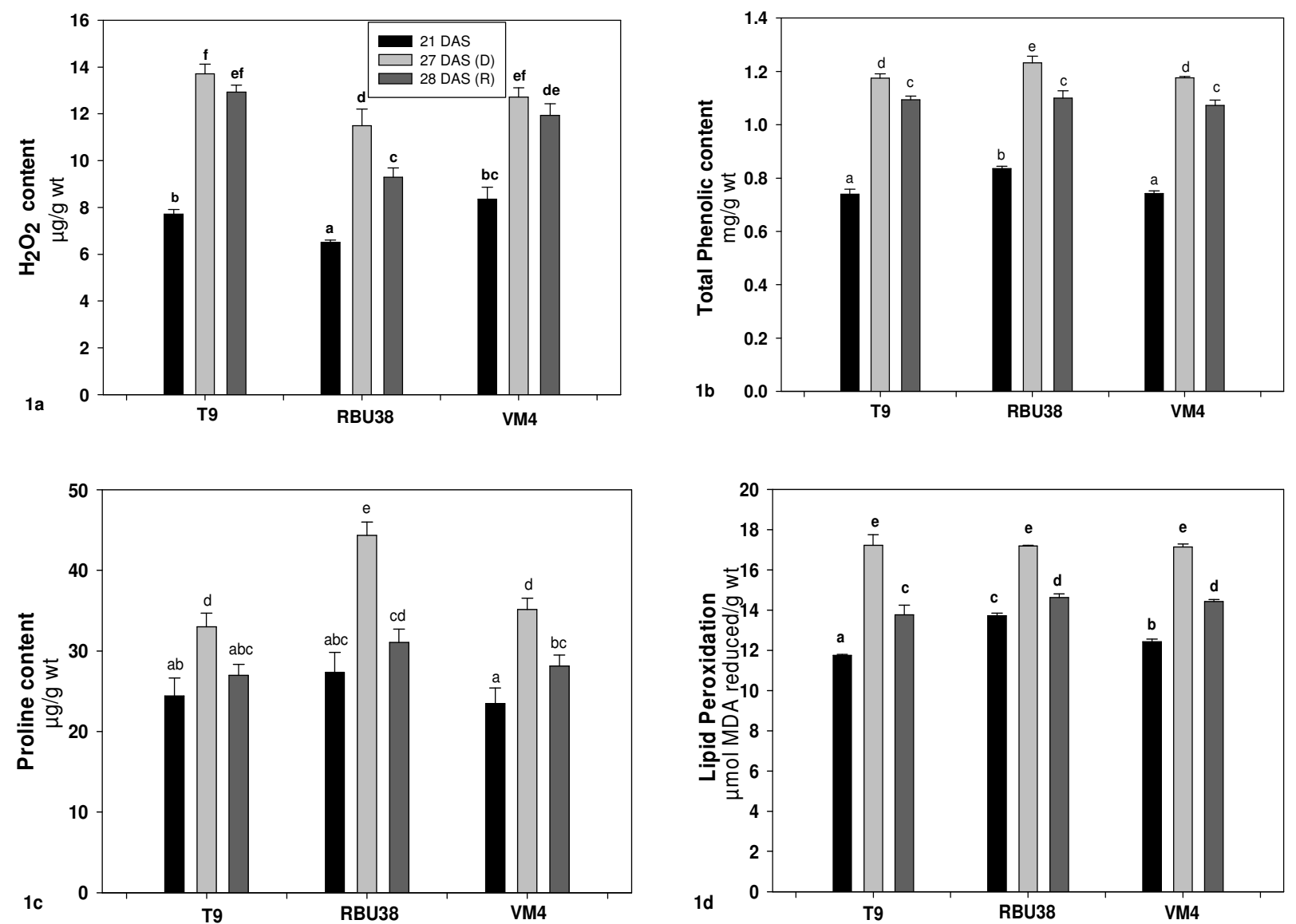

Fig. 1. Effect of drought stress on biochemical parameters of $V$. mungo leaves. a: $\mathrm{H}_{2} \mathrm{O}_{2}$ content ( $\mu \mathrm{g} \mathrm{g}^{-1}$ wt.); b: total phenolic content ( $\mathrm{mg} \mathrm{g}^{-1} \mathrm{wt}$.); c: Proline content ( $\mathrm{g} \mathrm{g}^{-1} \mathrm{wt}$.); lipid peroxidation ( $\mu$ mol MDA reduced g ${ }^{-1}$ wt.) Bars are mean \pm SD; bars followed by same alphabets are not significantly different at $\mathrm{p} \leq 0.05$ according to ANOVA and DMRT. DAS: days after sowing, D: 3 days under drought stress, R, recovery.

stomatal regulation of $\mathrm{CO}_{2}$, together with an increased accumulation of carbohydrates, lipid peroxidation (LP) and disturbance of water balance (Allen and Ort, 2001). In plants tolerant to drought like RBU38, the photosynthetic machinery may be protected from damage mainly by biochemical modulation specifically the antioxidant mechanism as noted in the subsequent results.

In the present study higher level of $\mathrm{H}_{2} \mathrm{O}_{2}$ content was observed in T9 plants at 27 DAS (D) and 28 DAS (R) among all three cultivars (Fig. 1a). He et al. (2011) observed higher level of $\mathrm{H}_{2} \mathrm{O}_{2}$ in sensitive genotypes when compared with tolerant genotypes in wheat. Although, $\mathrm{H}_{2} \mathrm{O}_{2}$ is an important indicator and signalling molecule for stressed plants higher $\mathrm{H}_{2} \mathrm{O}_{2}$ content contributed to oxidative stress which was aggravated under drought.

All plants of blackgram showed an increase in total phenolics at 27 DAS (D) and on recovery, a decrease was observed but remained higher than that of the control plants (Fig. 1b). Least increase in total phenolics was observed in RBU38 plants while T9 and VM4 plants showed almost same pattern under short-term drought stress as well as on recovery. Phenolic compounds provide protection to plants to biotic and abiotic stress (Chakraborty et al., 2008; Mandal et al., 2010; Jha et al., 2013; Pandey et al., 2014). 
Increased proline content was observed for all three varieties against three days of short-term drought stress and higher accumulation was observed in RBU38 plants when compared with T9 and VM4 plants (Fig. 1c). After recovery, decreased proline content was observed but it remained higher for each variety when compared with the control plants of the same variety. Studies of plants under drought stress indicate proline accumulation as a protective behaviour (Alam et al., 2010; Keyvan, 2010; Yazdanpanah et al., 2011; Alam et al., 2013). Turkan et al. (2005) observed higher proline content in drought tolerant plants in comparison to sensitive plants. Higher accumulation of proline in RBU38 plants is indicative of its drought tolerant property and may be responsible for limited damage to the photosynthetic machinery and preserve membrane integrity.

Production of ROS under drought stress damages the structure of protein, DNA and lipids (Apel and Heribert, 2004) estimated in terms of malondialdehyde (MDA; volatile aldehyde). All plants of blackgram showed an increase in MDA content at 27 DAS i.e. under drought stress, the least being in RBU38 and highest in T9. On recovery decrease was observed but content was more than that of relative control plants (Fig. 1d), which indicates that the values may eventually decrease to the levels of the control. Least lipid peroxidation was observed in RBU38 plants among all blackgram varieties under drought stress as well as on recovery. Higher level of lipid peroxidation is observed in drought sensitive plants when compared to tolerant plants (Turkan et al., 2005).

\section{Conclusion}

The present study shows that the performance of RBU38 plants under short-term drought stress is better in comparison to T9 and VM4 plants. The biochemical parameters studied indicate a specific pattern in the RBU8 which may be correlated with its drought tolerant property viz., least reduction in chlorophyll content and lipid peroxidation. Preservation of the photosynthetic machinery as well membrane integrity, which faces the maximum and the most visible damage under drought stress mainly due to the activation of antioxidant machinery in RBU38 can be attributed to its drought tolerant character. This is evident by the rapid increase in proline content in the RBU38 plants which plays a protective role. Similarly, a modulation in the $\mathrm{H}_{2} \mathrm{O}_{2}$ content, which is generally implicated to increased oxidative damage to cell, is also noted. It is to be noted that despite causing oxidative stress to plants, $\mathrm{H}_{2} \mathrm{O}_{2}$ at physiologically permissible concentration is considered to be a vital signalling molecule that initiates several protective molecular mechanisms in the cell and may play an important part in the drought tolerant character of RBU38. These parameters may be utilised to screen potential varieties and incorporated in plant breeding experiments to increase the performance of legume plants in general and blackgram in particular in terms of yield under stress conditions.

\section{Competing interests}

The authors declare that they have no competing interests.

\section{Acknowledgments}

The authors thank Professor Aditya Shastri, Vice Chancellor, Banasthali Vidyapith, India for providing the necessary facilities. The work is funded through a UGC, Govt. of India, Major Research Project to DC. SP thankfully acknowledge UGC for fellowship.

\section{References}

Alam, I., S. A. Sharmin, K. H. Kim, J. K. Yang, M. S. Choi, and B. H. Lee. 2010. Proteome analysis of soybean roots subjected to short-term drought stress. Plant Soil 333: 491-505. doi: 10.1007/s11104-010-0365-7

Alam, M. M., M. Hasanuzzaman, K. Nahar, and M. Fujita. 2013. Exogenous salicylic acid ameliorates short-term drought stress in mustard (Brassica juncea L.) seedlings by up-regulating the antioxidant defense and glyoxalase system. Australian Journal of Crop Science 7(7): 1053-1063.

Alexieva, V., I. Sergiev, S. Mapellis, and E. Karanov. 2001. The effect of drought and ultraviolet radiation on growth and stress markers in pea and wheat. Plant Cell and Environment 24: 1337-1344. doi: 10.1046/j.1365-3040.2001.00778.x

Allen, D. J., and D. R. Ort. 2001. Impact of chilling temperatures on photosynthesis in warm climate plants. Trends in Plant Science 6: 36-42. doi: 10.1016/S1360-1385(00)01808-2

Alpert, P., and M. J. Oliver. 2002. Drying without dying. In: Desiccation and survival in plants: drying without dying. Black M, Pritchard HW (eds). CABI publishing, Oxford and New York, pp 1-45. doi: 10.1079/9780851995342.0003

Apel, K., and H. Heribert. 2004. Reactive oxygen species: metabolism, oxidative stress, and signal transduction. Annual Review of Plant Biology 55: 373-399. doi: 10.1146/annurev.arplant.55.031903.141701 PMid: 15377225

Arnon, D. I. 1949. Copper enzymes in isolated chloroplasts: polyphenol oxidases in Beta vulgaris. Plant Physiology 24: 1-15. doi: 10.1104/pp.24.1.1 PMid:16654194

Arulbalachandran, D., L. Mullainathan, S. Velu, and C. Thilagavathi. 2010. Genetic variability, heritability and genetic advance of quantitative traits in black gram by effects of mutation in field trail. African Journal of Biotechnology 9(19): 2731-2735.

Baisak R, Rana D, Acharya PBB, Kar M (1994). Alterations in the activities of active oxygen scavenging enzymes of wheat leaves subjected to water stress. Plant Cell and Physiology. 35:489-495.

Bates, L. S., R. P. Waldren, and Teare, I. D. 1973. Rapid determination of free proline for water-stress studies. Plant Soil 39: 205-207. doi: 10.1007/BF00018060

Borade, V. P., S. S. Kadam, and D. K. Salunkhe. 1984. Changes in phytate, phosphorus and minerals during germination and cooking of horse gram and moth bean. Plant Foods for 
Human Nutrition 34(2): 151-157. doi: 10.1007/BF01094843

Bray, E. A. 1997. Plant responses to water deficit. Trends in Plant Science 2(2): 48-54. doi: 10.1016/S1360-1385(97)82562-9

Chakraborty, D., D. Sircar, and A. Mitra. 2008. Phenylalanine ammonia-lyase- mediated biosynthesis of 2-hydroxy-4methoxy benzaldehyde in roots of Hemidesmus indicus. Journal of Plant Physiology 165(10): 1033-1040. doi: 10.1016/j.jplph.2007.09.002 PMid:18023917

De Vos, C. H. R., H. Schat, R. Vooijs, and W. H. O. Ernst. 1989. Copper-induced damage to the permeability barrier in roots of Silene cucubalus. Plant Physiology 135: 164-179. doi: 10.1016/S0176-1617(89)80171-3

He, L., X. Jia, Z. Gao, and R. Li. 2011. Genotype-dependent responses of wheat (Triticum aestivum L.) seedlings to drought, UV-B radiation and their combined stresses. African Journal of Biotechnology 10(20): 4046-56.

Jha, P., R. Jindal, and D. Chakraborty. 2013. HPLC quantification of phenolic acids from Vetiveria zizanioides (Linn.) Nash. and its antioxidant and antimicrobial activity. Journal of Pharmaceutics 2013: 1-6. Article ID 270472.

Keyvan, S. 2010. The effects of drought stress on yield, relative water content, proline, soluble carbohydrates and chlorophyll of bread wheat cultivars. Journal of Animal \& Plant Sciences 8(3): 1051-1060.

Kundu, S., D. Chakraborty, and A. Pal. 2011. Proteomic analysis of salicylic acid induced resistance to Mungbean Yellow Mosaic India Virus in Vigna mungo. Journal of Proteomics 74(3): $\quad 337-349 . \quad$ doi: $\quad 10.1016 / j . j p r o t .2010 .11 .012$ PMid:21130907

Mandal, S. M., D. Chakraborty, and S. Dey. 2010. Phenolic acids are the signaling molecule in plant-microbe symbioses. Plant Signalling \& Behavior 5(4): 359-368. doi: 10.4161/psb.5.4.10871 PMid:20400851

Pandey, S., S. Ror, and D. Chakraborty. 2014. Analysis of biochemical responses in Vigna mungo varieties subjected to drought stress and possible amelioration. International Journal of Scientific Research in Agricultural Sciences 1(1): 6-15. doi: 10.12983/ijsras-2014-p0006-0015

Quan, L., B. Zang, W. Shi, and H. Li. 2008. Hydrogen peroxide in plants: a versatile molecule of the reactive oxygen species network. Journal of Integrative Plant Biology 50: 2-18. doi: 10.1111/j.1744-7909.2007.00599.x PMid:18666947

Saravanakumar, D., S. Harish, M. Loganathan, R. Vivekananthan, L. Rajendran, T. Raguchander, and R. Samiyappan. 2007. Rhizobacterial bioformulation for the effective management of Macrophomina root rot in mungbean. Archives of Phytopathology and Plant Protection 40(5): 323-337. doi: 10.1080/03235400600587326

Singleton, V. L., R. Orthofer, and R. M. Lamuela-Raventos. 1999. Analysis of total phenol and other oxidation substrates and antioxidants by means of Folin-Ciocalteau reagent. Methods Enzymology 299: 152-78. doi: 10.1016/S0076-6879(99)99017-1

Smirnoff, N. 1993. The role of active oxygen in the response of plants to water deficit and desiccation. New Phytologist 125: 27-58. doi: 10.1111/j.1469-8137.1993.tb03863.x

Souframanien, J., and T. Gopalakrishna. 2006. ISSR and SCAR markers linked to the mungbean yellow mosaic virus (MYMV) resistance gene in blackgram [Vigna mungo (L.)
Hepper]. Plant Breeding 125: 619-622. doi: 10.1111/j.1439-0523.2006.01260.x

Trippi, V. S., X. Gidrol, and A. Pradet. 1989. Effects of oxidative stress by oxygen and hydrogen peroxide on energy metabolism and senescence in oat leaves. Plant Cell Physiology 30: 210-217.

Turkan, I., M. Bor, F. Ozdemir, and H. Koca. 2005. Differential responses of lipid peroxidation and antioxidants in the leaves of drought-tolerant $P$. acutifolius Gray and drought-sensitive $P$. vulgaris $L$. subjected to polyethylene glycol mediated water stress. Plant Science 168: 223-231. doi: 10.1016/j.plantsci.2004.07.032

Walters, C., J. M. Farrant, N. W. Pammenter, and P. Berjak. 2002. Desiccation stress and damage. In: Desiccation and survival in plants: drying without dying. Black M, Pritchard HW (eds). CABI publishing, Oxford and New York, pp 263-293. doi: $10.1079 / 9780851995342.0263$

Wang, J., D. Q. Li, and L. S. Gu. 2002. The response to water stress of the antioxidant system in maize seedling roots with different drought resistance. Acta Botanica Boreali-Occidentalia Sinica 22: 285-290.

Yazdanpanah, A. Baghizadeh, and F. Abbassi. 2011. The interaction between drought stress and salicylic and ascorbic acids on some biochemical characteristics of Satureja hortensis. African Journal of Agricultural Research 6(4): 798-807. 